\title{
Gastric cancer with situs inversus totalis: does it really create difficulties for surgeons?
}

\author{
Ebubekir Gündeş, Durmuş Ali Çetin, Ulaş Aday, Hüseyin Çiyiltepe, Emre Bozdağ, Aziz Serkan Senger, \\ Selçuk Gülmez, Kamuran Cumhur Değer, Orhan Uzun, Erdal Polat \\ Gastroenterological Surgery Department, Kartal Koşuyolu High Speciality and Training Hospital, Istanbul, Turkey
}

Gastroenterology Rev 2018; 13 (1): 47-51

DOI: https://doi.org/10.5114/pg.2018.74563

Key words: situs inversus totalis, gastric cancer, gastrectomy.

Address for correspondence: Ebubekir Gündeş MD, Gastroenterological Surgery Department, Kartal Koşuyolu High Speciality and Training Hospital, Denizer cad. No: 22, 34000 Istanbul, Turkey, phone: +90 5058606740, e-mail: ebubekir82@hotmail.com

\begin{abstract}
Introduction: Situs inversus totalis (SIT) is a very rare condition that is seen at a rate of one in about $6000-8000$ births.

Aim: To offer a general view on the coexistence of SIT and gastric cancer, accompanied by a literature review.

Material and methods: Within the scope of this study, the case of a patient with gastric adenocarcinoma and SIT has been presented. Previous research on gastric cancer cases with SIT was reviewed through a comprehensive search of the PubMed, MEDLINE, and Google Scholar databases. The keywords used to conduct this research were "situs inversus totalis and gastric cancer," "situs inversus totalis and gastric malignant," and "situs inversus totalis and gastric resection." The database search covered English studies published between 2000 and 2016.

Results: The results of our literature review revealed 20 studies of patients with gastric cancer and SIT, and 21 related cases. Overall, 12 of the patients were male, 9 were female, and their mean age was $61.8 \pm 10.97$ years. The vascular assessment data showed that three out of the 13 mentioned cases had vascular anomalies. Eleven of the patients had laparoscopic resections, and one of the patients that had a surgical procedure exhibiting a postoperative mechanical obstruction.

Conclusions: The coexistence of SIT and gastric cancer is a very rare condition, and a careful preoperative radiological assessment should be conducted because there can be accompanying vascular anomalies. Laparoscopies and robotic surgeries can be performed for suitable patients at experienced centres, consistent with oncological principles.
\end{abstract}

\section{Introduction}

Situs inversus totalis (SIT) is a very rare condition that is seen at a rate of one in about $6000-8000$ births [1]. In this situation, the organs or organ systems are transposed to the opposite side of the body from their normal locations (mirror image of the normal), and it is most often detected during a radiological assessment [1-3]. The coexistence of SIT and gastric cancer in the literature is limited to a few case reports $[4,5]$. In these cases, the research has shown that laparoscopic and open gastrectomies have been performed successfully. Moreover, the surgical procedure to be performed does not need to change, even though the anatomy of these patients is different.

\footnotetext{
Aim

Here we present the case of a patient diagnosed with gastric cancer and SIT, accompanied by a review of English studies on this subject.
}

\section{Material and methods}

Our study presents a case of gastric cancer with SIT and offers a discussion in light of the relevant literature. We searched for published studies of gastric cancer with SIT using different keyword combinations, including "situs inversus totalis and gastric cancer", "situs inversus totalis and gastric malignant", and "situs inversus totalis and gastric resection" in the PubMed, MEDLINE, and Google Scholar databases. Those studies published between January 1, 2000 and December 1, 2016 were reviewed, and any with full-text versions available and sufficient details on the patients were included in our study. Literature reviews and repeated reports were excluded from the study. The data recorded from the previous studies included the date of publication, age, sex, tumour location, existence of a vascular anomaly, surgical procedure performed, lymph node dissection, tumour/node/metastasis (TNM) staging, and postoperative complications. 


\section{Results}

\section{Case report}

A 72-year-old female patient presented to our clinic with complaints of epigastric pain and burning. Her medical history showed no known comorbidities, and the abdominal and lymph node examinations did not reveal any problems. An oesophagogastroscopy revealed a lesion of about $1 \times 1 \mathrm{~cm}$ in size with an ulcerated surface, located in the antrum close to the pylorus, with a slight tumorous appearance. Her biopsy results showed that it was an adenocarcinoma. A pulmonary

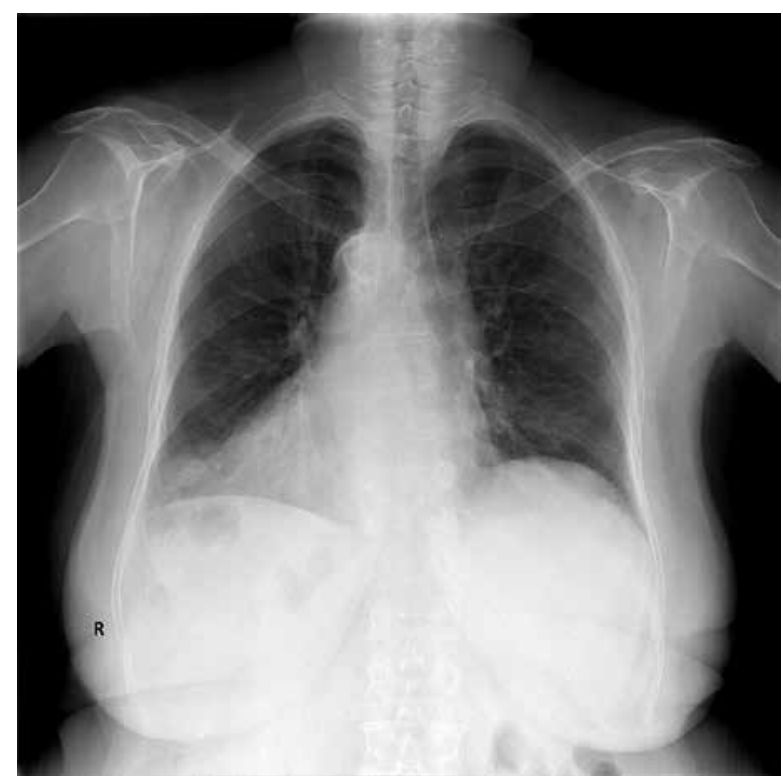

Figure 1. X-ray of the chest taken, showing dextrocardia

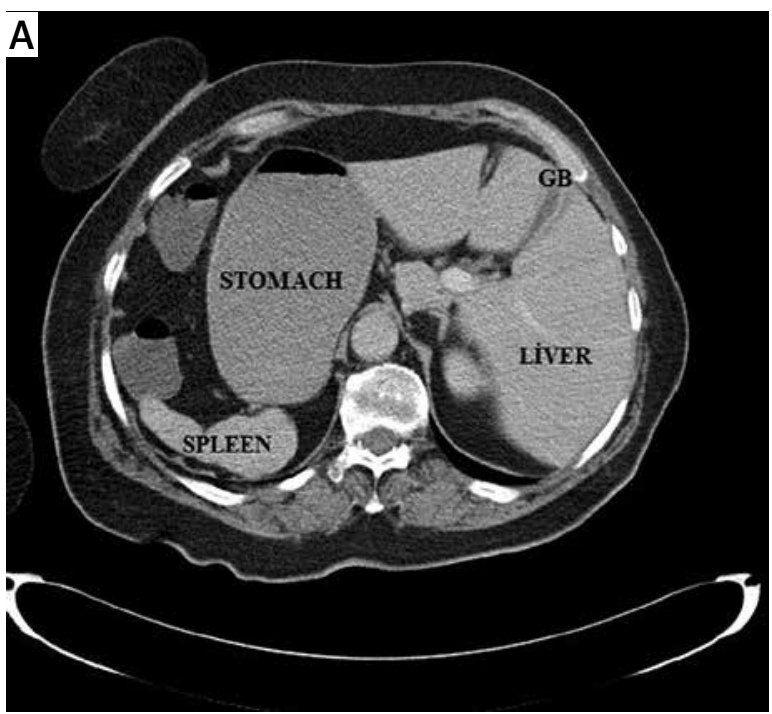

Figure 2. A - Abdominal computed tomography revealed a complete right-left reversal of the abdominal organs, $\mathbf{B}$ - thickened wall of gastric antrum without distant metastasis

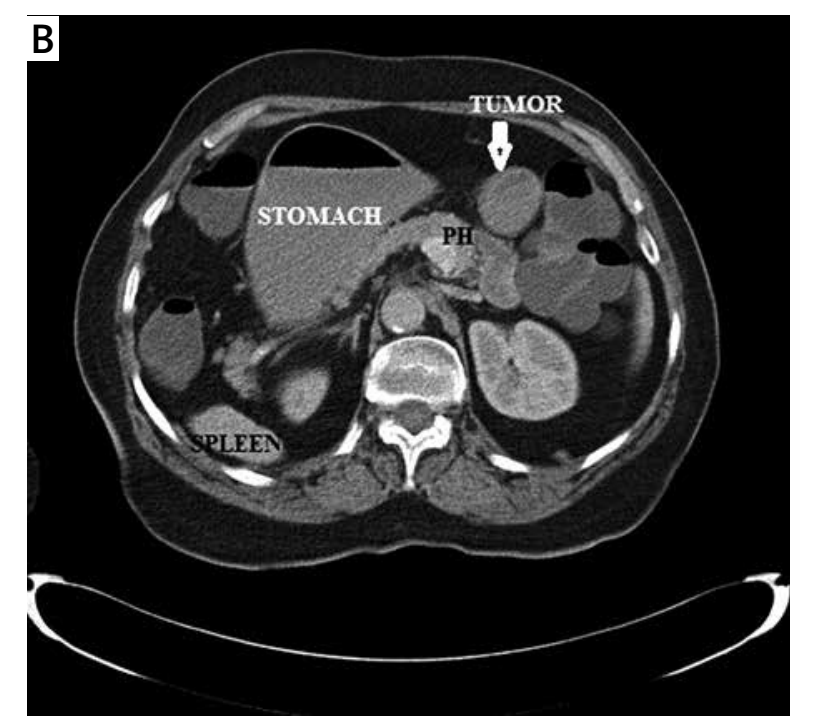

radiograph showed dextrocardia (Figure 1), while the thoracoabdominal computerised tomography (CT) revealed SIT (Figures 2 A, B). There was no evidence of intra-abdominal acid, distant organ metastasis, peritoneal carcinomatosis, pathological lymph nodes, or vascular anomalies.

Endoscopic ultrasonography (EUS) was applied to the patient for endoscopic mucosal resection compliance. The EUS was evaluated as T1NO. An endoscopic mucosal resection was recommended for this patient, but a surgical procedure was planned since she and her family did not accept the recommendation. Subsequently, a distal subtotal gastrectomy and D1 lymph node dissection were performed via laparotomy. Billroth 2 gastroenterostomy anastomosis and Braun's enteroenterostomy was performed for reconstruction. The operating time was $150 \mathrm{~min}$ and blood loss was $100 \mathrm{ml}$. The patient was then discharged on the eighth postoperative day without any problems. The pathological analysis of this patient revealed a tumorous lesion of approximately $1.5 \times 1 \mathrm{~cm}$, compatible with well differentiated (G1) adenocarcinoma, which had involvement up to the submucosa. None of the excised 17 lymph nodes exhibited metastasis (T1bNOM0). In light of these results, the patient was taken into the follow-up program without any adjuvant therapy.

\section{Literature review}

In total, 21 cases and 20 articles published in English between 2000 and 2016 were found through a comprehensive search of the PubMed, Google Scholar, and MEDLINE databases. Twelve (57.1\%) of these patients were male, 9 (42.9\%) were female, and their 
mean age was $61.8 \pm 10.97$ years old. The tumour localisations were in the antrum in $13(61.9 \%)$ patients, corpus in 2 (9.5\%) patients, esophagogastric junction in $2(9.5 \%)$ patients, corpus antrum junction in $2(9.5 \%)$ patients, and cardia in 1 (4.8\%) patient. In 1 (4.8\%) of the patients the tumour localisation was not specified.

Although vascular anomalies were seen in 10 (47.6\%) cases, they were not specified in $8(38.1 \%)$ of them. In 1 out of the 3 (14.3\%) patients with vascular anomalies the left hepatic artery exited from the superior mesenteric artery, in one the left gastric artery exited from the aorta, and in the final one the left gastric artery was double branching.

Nineteen of the patients received curative surgeries, with 11 of these having had laparoscopic resections. Two of the patients did not receive curative procedures; one of them received a palliative surgery, and no surgical procedure was performed on the other. Only 1 of these cases developed a mechanical obstruction. The demographic and clinical characteristics of the patients (20 studies, 21 patients) have been summarised in Table I [6-25].

\section{Discussion}

Situs inversus totalis is a congenital anomaly with an asymptomatic course, and it develops via the clockwise rotation of the embryonic midgut at $270^{\circ}$, instead of a counter-clockwise rotation at $270^{\circ}$. Thus, all of the thoracic and abdominal visceral organs are located symmetrically according to the midline in reverse. In other words, SIT is the mirror image of the normal [1]. Situs inversus can include both the thoracic and abdominal cavities (totalis), or only one cavity (partial). The term situs solitus, on the other hand, refers to the normal localisation of the bodily organs [1, 2].

The aetiology of situs inversus remains a controversial issue. It has been suggested that it is related to a genetic defect occurring during the second week of the embryonal period [2]. It can be accompanied by pathologies like bronchiectases (Kartagener syndrome), polysplenia, and genitourinary anomalies [3-5]. In addition, cancers of various organs have been seen in patients with situs inversus [26, 27]. Allen [28] first described a case of gastric carcinoma in a male patient with situs inversus in 1936; however, this condition has been limited to case reports in the literature $[2,17]$ Generally, it has been suggested that there is no direct relationship between SIT and gastric cancer [15, 23].

In cases of SIT, the most significant preoperative stage, especially before performing laparoscopic procedures, is the careful and cautious assessment of anatomical variations using preoperative imaging methods $[8,16]$. If possible, CT angiography is recommended for the detection of accompanying vascular anomalies [29]. In our case, the CT was helpful in unveiling the local and vascular structures.

For SIT patients, the treatment modality is no different than that for normal gastric cancer. The previous literature has shown that these patients most often received successful surgical treatments [6-24]. For example, open, assisted or total laparoscopic, and assisted robotic gastrectomy procedures have been performed successfully. Yamaguchi et al. [8] reported the first laparoscopy-assisted distal gastrectomy case in 2003. Following this case, 6 more cases of laparoscopy-assisted distal gastrectomies were reported. Min et al. [19] published the first case of a totally laparoscopic distal gastrectomy in 2013, followed by a 2015 study by Morimoto et al. [21] in which the authors presented the first totally laparoscopic total gastrectomy case. Moreover, Kim et al. [16] presented the first and only robot-assisted distal gastrectomy case in the literature in 2012.

Some of the cases in the literature also received additional organ resections alongside the gastric resections. Among these, it was reported that 2 patients had a splenectomy and cholecystectomy, 1 had a low anterior resection, and 1 had a cholecystectomy [6, 7, 14, 24].

Situs inversus totalis can pose a challenge during surgery because of the extraordinary anatomy of these patients. Some surgeons have recommended that the operator and assistant positions should be reversed, especially during laparoscopic surgeries $[11,13,18]$. However, there are other authors who have reported successful laparoscopic procedures in the normal positions [14]. In our case, the surgeon and assistant worked in their standard places, successfully completing the surgical procedure.

The structure of gastric cancer is complex. The lymph node status alone may not be sufficient to show the disease. Appropriate lymph node dissection should be performed in patients with all gastric cancers [30].

When the postoperative complications were investigated, it was seen that the rate of complications was very low, with a mechanical obstruction seen in only one case $[15,18]$.

\section{Conclusions}

The coexistence of SIT and gastric cancer is a very rare condition. Although it has been reported that surgeons might experience challenges because of the extraordinary anatomy of these patients, the cases presented in the literature were reported to have been treated successfully. A careful radiological assessment should be conducted preoperatively because there might be accompanying anomalies, especially vascular 


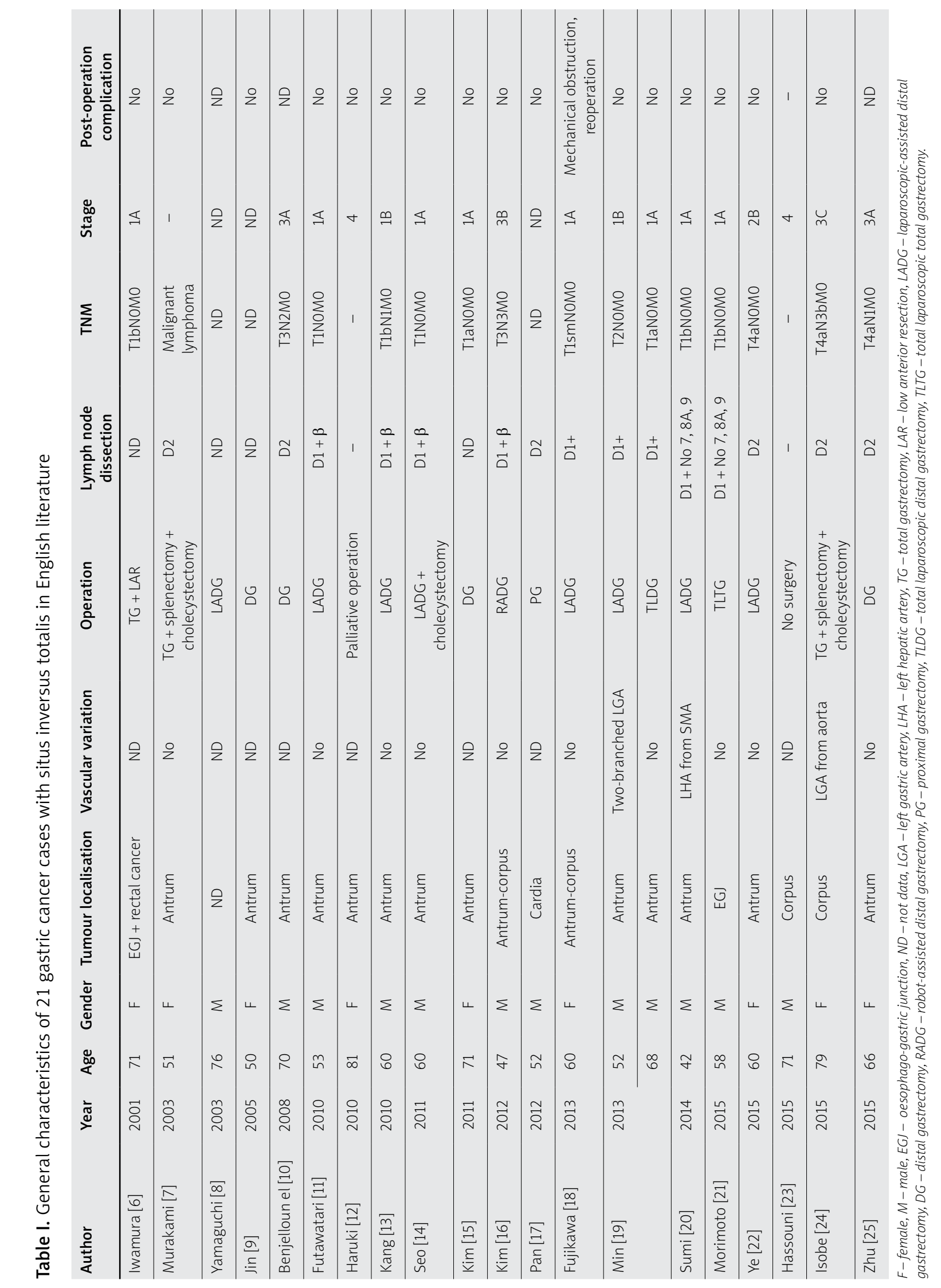


ones. Overall, laparoscopies and robotic surgeries can be performed for suitable patients at experienced centres, consistent with oncological principles.

\section{Conflict of interest}

The authors declare no conflict of interest.

\section{References}

1. Blegen HM. Surgery in situs inversus. Ann Surg 1949; 129: 244-59.

2. Gray SW, Skandalakis JE. Embryology for Surgeons: The Embryological Basis of the Treatment of Congenital Defects. WB Saunders, Philadelphia 1972; 880-3.

3. Katsuhara K, Kawamoto S, Wakabayashi T, et al. Situs inversus totalis and Kartagener's syndrome in a Japanese population. Chest 1972; 61: 56-61.

4. Niikawa N, Kohsaka S, Mizumoto M, et al. Familial clustering of situs inversus totalis, and asplenia and polysplenia syndromes. Am J Med Genet 1983; 16: 43-7.

5. Kaynar K, Ulusoy S, Gul S, et al. Renal hypoplasia and situs inversus totalis. Nephrology (Carlton) 2005; 10: 189-91.

6. Iwamura T, Shibata N, Haraguchi Y, et al. Synchronous double cancer of the stomach and rectum with situs inversus totalis and polysplenia syndrome. J Clin Gastroenterol 2001; 33: 148-53.

7. Murakami S, Terakado M, Misumi M, et al. Situs inversus totalis with malignant lymphoma of the stomach: report of a case. Surg Today 2003; 33: 533-6.

8. Yamaguchi S, Orita H, Yamaoka T, et al. Laparoscope-assisted distal gastrectomy for early gastric cancer in a 76-year-old man with situs inversus totalis. Surg Endosc 2003; 17: 352-3.

9. Jin SH, Kim WW, Oh SH. Radical subtotal gastrectomy in early gastric cancer patient with situs inversus totalis. J Korean Surg Soc 2005; 69: 263-5.

10. Benjelloun el B, Zahid FE, Ousadden A, et al. A case of gastric cancer associated to situs inversus totalis. Cases J 2008; 1 : 391.

11. Futawatari N, Kikuchi S, Moriya H, et al. Laparoscopy-assisted distal gastrectomy for early gastric cancer with complete situs inversus. Surg Today 2010; 40: 64-7.

12. Haruki T, Maeta Y, Nakamura $S$, et al. Advanced cancer with situs inversus totalis associated with KIF3 complex deficiency: report of two cases. Surg Today 2010; 40: 162-6.

13. Kang BH, Lee SL, Hur H, et al. Laparoscopy assisted subtotal gastrectomy in gastric cancer patient with situs inversus in Korea. J Korean Surg Soc 2010; 79: 513-7.

14. Seo KW, Yoon KY. Laparoscopy-assisted distal gastrectomy for early gastric cancer and laparoscopic cholecystectomy for gallstone with situs inversus totalis: a case report. J Korean Surg Soc 2011; 81 Suppl 1: S34-8.

15. Kim YW, Ryu H, Kim DS, et al. Double primary malignancies associated with colon cancer in patients with situs inversus totalis: two case reports. World J Surg Oncol 2011; 9: 109.

16. Kim HB, Lee JH, Park DJ, et al. Robot-assisted distal gastrectomy for gastric cancer in a situs inversus totalis patient. J Korean Surg Soc 2012; 82: 321-4.
17. Pan K, Zhong D, Miao X, et al. Situs inversus totalis with carcinoma of gastric cardia: a case report. World I Surg Oncol 2012; 10: 263.

18. Fujikawa H, Yoshikawa T, Aoyama T, et al. Laparoscopy-assisted distal gastrectomy for an early gastric cancer patient with situs inversus totalis. Int Surg 2013; 98: 266-70.

19. Min SH, Lee CM, Jung HJ, et al. Laparoscopic distal gastrectomy in a patient with situs inversus totalis: a case report. J Gastric Cancer 2013; 13: 266-72.

20. Sumi Y, Maehara R, Matsuda Y, et al. Laparoscopy-assisted distal gastrectomy in a patient with situs inversus totalis. JSLS 2014; 18: 314-8.

21. Morimoto M, Hayakawa T, Kitagami H, et al. Laparoscopic-assisted total gastrectomy for early gastric cancer with situs inversus totalis: report of a first case. BMC Surg 2015; 15: 75.

22. Ye MF, Tao F, Xu GG, et al. Laparoscopy-assisted distal gastrectomy for advanced gastric cancer with situs inversus totalis: a case report. World J Gastroenterol 2015; 21: 10246-50.

23. Hassouni A, Haddad H, Tawfiq N, et al. Gastric cancer with situs inversus. Int J Cancer Stud Res 2015; 4: 86-7.

24. Isobe T, Ogata S, Kaku H, et al. A patient with advanced gastric cancer and situs inversus totalis: report of a case. Kurume Med J 2015; 61: 73-6.

25. Zhu H, Yang K, Hu JK. Gastrectomy for gastric carcinoma with situs inversus totalis: case report and literature review. Hippokratia 2015; 19: 360-2.

26. Huh JW, Kim HR, Cho SH, et al. Laparoscopic total mesorectal excision in a rectal cancer patient with situs inversus totalis. J Korean Med Sci 2010; 25: 790-3.

27. Ujiie N, Nakano T, Kamei T, et al. Thoracoscopic esophagectomy for esophageal cancer with situs inversus totalis: a case report and literature review. Gen Thorac Cardiovasc Surg 2016; 64: 359-62.

28. Allen FRWK. A case of malignant tumor of the stomach in a male with transposition of the viscera. Indian Med Gaz 1936; 71: 32.

29. Napoli A, Fleischmann D, Chan FP, et al. Computed tomography angiography: state-of the-art imaging using multidetector-row technology. J Comput Assist Tomogr 2004; 28 (Suppl 1): S32-45.

30. Szczepanik AM, Paszko A, Szura M, et al. Alternative staging of regional lymph nodes in gastric cancer. Prz Gastroenterol 2016; 11: 145-9.

Received: 16.04.2017

Accepted: 1.06.2017 